\title{
As Práticas dos Gestores Públicos em Portugal e os Códigos de Ética ${ }^{1}$
}

\section{The Practices of Public Managers in Portugal and the Codes of Ethics}

\author{
João Bilhim \\ Instituto Superior de Ciências Sociais e Políticas (ISCSP) da \\ Universidade de Lisboa (UL) - Lisboa, Portugal
}

\begin{abstract}
Resumo: O conjunto de ideias e programas conhecido por "Nova Gestão Pública" favoreceu uma maior capacitação dos dirigentes, expressa através de maior grau de liberdade no processo de tomada de decisão, ou seja, menor controlo a priori e, em particular, de formação adequada (OCDE 1996; BILHIM, NEVES, 2005). Neste artigo, ultrapassando a dualidade Kant/Aristóteles e situando a ética, na perspetiva de Rawls, na tensão entre a justiça e a liberdade, questiona-se se a ética é um ponto que se atinge ou, antes, uma direção que se toma, propondo instrumentos e processos que sirvam de "arquitetura ética" para um comportamento mais íntegro dos dirigentes da Administração.
\end{abstract}

Palavras-chave: Ética. Gestão Pública. Cultura Organizacional.

\begin{abstract}
The set of ideas and programs, known as New Public Management (NPM), enable the empowerment of leaders, through a greater degree of freedom in decision-making, by means of less a priori control and, appropriate training (OECD 1996); (Bilhim, Neves 2005). In this article, overcoming the duality Kant/Aristotle and placing ethics, according to Rawls, in the tension between justice and freedom, we question whether ethics is an end-point or rather a direction to be chosen. In addition, we propose instruments and processes that can serve as "ethic architecture" to guide the ethics of public service.
\end{abstract}

Keywords: Ethics. Public Management. Organizational Culture.

\section{Introdução}

Tem-se assistido a um forte crescimento do interesse pela ética na administração pública, a tal ponto que autores e até as organizações como

1 Recebido em: 3/4/2014

Revisado em: 3/10/2014

Aprovado em: 22/10/2014 
a AmericanSociety for PublicAdministration (ASPA) defendem a sua autonomização como campo de estudo.

Por outro lado, a Organização para a Cooperação e Desenvolvimento Económico (OCDE) vem dar ênfase e atualidade ao tema, nomeadamente através da produção de numerosos estudos e trabalhos, consubstanciando as suas preocupações e os seus interesses por esse assunto na criação de uma área de intervenção específica - Ethics and Corruption. Nesse sentido, é preconizado pela OCDE que aos tradicionais 3Es - economia, eficácia e eficiência - se acrescente um outro: o E de ética. (OCDE 1996)

A própria Organização das Nações Unidas (ONU), através da United Nations Online Network in Public Administration and Finance (UNPAN), criou uma diretoria específica que aprofunda e estuda essa problemática.

A ética do serviço público ganhou grande atualidade para profissionais e acadêmicos, quer estritamente aplicada à Administração Pública em sentido estrito, quer aplicada a todas as organizações que em nome do Estado fornecem serviços públicos. É o caso, por exemplo, das organizações do terceiro setor ou de empresas que, sob contrato, prestam serviços aos cidadãos. (COOPER, 1994; FREDERICKSON, 1997)

Portugal não tem sido exceção. Com efeito, já o XII Governo, através da Resolução do Conselho de Ministros no . 18/93, de 18 de fevereiro de 1993, aprovou uma "Carta Deontológica do Serviço Público", publicada em 17 de março na edição nº 64 do Diário da República, destinada aos funcionários públicos da administração central, regional ou local, dirigentes ou não. O âmbito dessa carta deontológica não se aplicava ainda à intervenção do Estado na sua ação mais alargada de governança ${ }^{2}$, ou seja, não contemplava as organizações de trabalhadores do terceiro setor e empresas que em nome do Estado aplicavam políticas públicas.

\footnotetext{
2 De acordo com o Banco Mundial (Governance and Development, de 1992), a governança consiste "no exercício da autoridade, controle, administração, poder de governo", ou seja, "é a maneira pela qual o poder é exercido na administração dos recursos sociais e económicos de um país apontando o desenvolvimento", exigindo ainda "a capacidade dos governos de planear, formular e implementar políticas e cumprir funções".
} 
O fator que terá desencadeado essa urgência parece andar associado ao movimento de reforma da Nova Gestão Pública, que eclodiu nos finais dos anos setenta em resultado das pressões de natureza económica, financeira e social, que levaram os governos a questionar e a repensar a estrutura da Administração Pública (MOZZICAFREDO, 2001; ARAÚJO, 2012). Esse movimento tem na sua gênese a mudança de paradigma da economia ocorrida nos anos setenta do século passado e ganhou força como programa de ação do "Consenso de Washington", como ficou consagrado (BILHIM, 2008). No âmbito desse movimento, procura-se uma "administração que trabalhe melhor e gaste menos". (FREDERICKSON, 1997)

A realidade atual de mudança em que vive a administração pública, perpassada por diversos fenómenos - downsizing, privatizações, parcerias público-privadas, reestruturações, reengenharia - levanta questões éticas não apenas no que diz respeito às consequências desses novos formatos organizacionais e de gestão, de clarificação de responsabilidades, do modo de atuação dos gestores/dirigentes que se encontram à frente dessas organizações e sua orientação relativamente afins, mas também no que concerne ao relacionamento com os cidadãos e ao seu estatuto como utilizadores. (BILHIM; NEVES 2005)

A ética do serviço público apresenta-se como uma inevitabilidade, e tanto assim é que países como os Estados Unidos, Austrália, Nova Zelândia, entre muitos outros, estão a levar a cabo diversas iniciativas e reformas sob essa égide.

Por outro lado, vive-se num tempo em que muitos salientam caracterizar-se por uma crise de valores, na qual a fugacidade e a relatividade dos fenómenos e dos acontecimentos são inelutáveis e tantos aspetos da relação entre o Estado e os cidadãos estão a ser postos em causa, nomeadamente através dos novos papéis do Estado. O seu novo papel passa pela transformação de um Estado produtor de serviços públicos num Estado regulador, atribuindo a produção a um conjunto enorme de novos operadores.

Os principais fatores de pressão que compelem a ética a ocupar na agenda de hoje um espaço central são, entre outros, as dificuldades mate- 
riais e de recursos; as necessidades cada vez mais crescentes e complexas da sociedade; a perspetiva crítica e atenta que a cidadania implica, nomeadamente a comunicação social; as questões de reestruturação e mudança da própria administração; a exigência, cada vez maior, de que os processos de decisão sejam mais amplamente participados na dinâmica evolutiva da sociedade.

A Nova Gestão Pública representou uma mudança de paradigma. A substituição de uma administração tradicional por uma administração por objetivos, baseada na meritocracia, não corresponde propriamente à introdução de uma nova técnica de gestão, tratando-se antes de uma nova postura cultural de quantos trabalham na Administração. Antes, à pergunta "o que fazem vocês quotidianamente na Administração?", obtinha-se a resposta - "interpreto e aplico a lei”. Era o reinado do paradigma jurídico. Agora, a resposta é outra - "melhoro permanentemente o que faço"; é que gerir é medir, medir é comparar e comparar impele à melhoria contínua. A interpretação e aplicação da lei deixou de ser um fim para se confinar a um meio.

Assim, a nova Gestão Pública acarretou mudanças na estratégia, no sistema administrativo, nos processos de trabalho para os funcionários e dirigentes, alterando os tradicionais sistemas de controlo sem que de forma eficaz tenha cuidado de criar sistemas novos.

Nesse contexto, a conduta dos dirigentes e dos gestores públicos ${ }^{3}$ condiciona fortemente o restante do corpo administrativo e afeta a imagem das organizações públicas que dirigem e, por consequência, a confiança dos cidadãos nas instituições, nomeadamente no Estado. A sua conduta encontra-se permanentemente numa espécie de montra sujeita ao escrutínio público de todos os cidadãos e, em particular, dos membros das equipas de trabalho que dirigem. Nessa medida, eles têm uma responsabilidade acrescida no exemplo que transmitem, dado o impacto da ges-

\footnotetext{
3 Os "dirigentes" superiores e intermédios são, de acordo com o Estatuto do Pessoal Dirigente da Administração (EPDA), os responsáveis não eleitos pela administração afetos à Administração Central, Regional e Local, Direta e Indireta do Estado; os "gestores públicos" são os responsáveis pela administração das empresas públicas, quer tenham a natureza de entidade pública empresarial, quer a de sociedade anónima de capital total ou parcialmente público. Neste artigo, são usadas as duas expressões por nos estarmos a referir a esta dupla realidade.
} 
tão pelo exemplo. Por isso é que se um comportamento ético e íntegro é indispensável para todos os trabalhadores e funcionários públicos, mais ainda o é para os dirigentes e gestores públicos. Mais do que pregar a conduta ética, importa, pois, praticá-la.

Chegados a esse ponto, importa entender qual o papel dos códigos de ética. Os códigos de ética procuram estandardizar e padronizar comportamentos, fornecendo uma boa base para as comparações externas (benchamark). São, genericamente, considerados necessários. Todavia, profissionais e acadêmicos acham que o seu impacto sobre o comportamento de funcionários e dirigentes é fraco. (PUGH, 1991, p. 18)

A razão dessa fraca utilidade liga-se ao facto de estes códigos serem em geral excessivamente genéricos e abstratos - e, consequentemente, se revelarem irrelevantes como guia da ação em contextos específicos ou, pelo contrário, tão específicos que se aplicam exclusivamente a uma situação ou contexto incapazes de servir de regra geral. Acresce que os códigos, na perspetival aristotélica, não transformam dirigentes corruptos em pessoas honestas e de carácter nem reduzem a discricionariedade em favor do interesse pessoal, institucional ou coletivo. (CHANDLER, 1994)

Para Aristóteles, as melhores flautas devem ser distribuídas aos melhores flautistas, porque é para serem bem tocadas que elas existem; não propriamente para produzirem boa música que nos beneficia a todos. A finalidade das flautas é produzir música excelente e aqueles que melhor cumprirem esta função deveriam ter as melhores flautas. (SANDEL, 2011, p. 197)

Nesse contexto, não se pode deixar de analisar a questão central da ética moderna, que passa pela densificação do eixo liberdade-justiça; de outra forma, examina-se o conflito entre liberdades, a minha e a dos outros, cuja harmonização se chama justiça (fairness). A tensão entre as várias liberdades está na baseada necessidade de se buscar um equilíbrio que contemple a satisfação, pelo menos em parte, dos desejos de todos. (RAWLS, 1993)

Ora, na busca desse equilíbrio, constata-se que a ética não é tanto um ponto que se conquiste ou um valor que se capitalize numa instituição 
bancária, mas, muito mais, uma direção que se toma e uma caminhada que nunca terá fim, em que o importante é não esmorecer.

\section{O Contexto do Problema}

O programa de reformas preconizado pela Nova Gestão Pública recomendava que os governos conduzissem a Administração como se de uma empresa se tratasse, reduzindo a regulamentação e a burocracia, ou seja, muitos sistemas de controlo; fomentando a externalização de atividades através da substituição dos monopólios públicos; reduzindo trabalhadores e dirigentes; exigindo aos funcionários sem formação específica a assunção de novas funções ligadas à gestão de contratos; fomentando a lógica de mercado através da competição entre serviços.

Ora, esse programa acarretou o derrube dos mecanismos tradicionais de controlo, dando, por um lado, maior capacitação e margem de decisão autónoma a funcionários, dirigentes e gestores públicos, e, por outro, criando "agências" públicas com maior autonomia administrativa, financeira e técnica. Acresce que a Nova Gestão Pública nunca cuidou de colocar na agenda a criação de novos sistemas de controlo, adequados à nova filosofia de condução da "coisa" pública que preconizava.

A filosofia da Nova Gestão Pública partilhava, de forma nunca confessada, o princípio do bom selvagem de Rousseau. No caso vertente, não é a sociedade que perverte; o que perverte é o sistema de regras da administração tradicional. Por isso, mal se libertem os funcionários, dirigentes e gestores públicos do espartilho das regras e normas tradicionais, como são bons por natureza, tudo correrá bem.

Muitas administrações públicas vivem atualmente dilemas e inconsistências entre as novas orientações estratégicas das reformas e os sistemas de controlo (POLLIT; BOUCKAERT 2004), o que acarretou problemas éticos nos funcionários e no sistema de regras e, particularmente, 
pode ter incentivado a corrupção ${ }^{4} \mathrm{e}$ aumentado as oportunidades de existirem fortes conflitos de interesses raramente declarados e assumidos.

Como a ética não diz respeito apenas aos funcionários mas também ao sistema. Apesar de as pessoas constituírem objeto de incidência da ética e o motor para a inversão de práticas e modos de atuação - assumindo por isso particular importância e certa complexidade o modo de as motivar, consciencializar e formar/preparar para uma postura e atuação ética -, os processos e sistemas organizacionais têm também uma importância relevante e até inevitável, não apenas com o contexto em que se desenrola a ação dos indivíduos, mas igualmente por servirem de guia para essa mesma ação. O sistema organizacional e o sistema comportamental influenciam-se e reforçam-se ou enfraquecem-se mutuamente.

Por isso, constituem situações favoráveis à corrupção: a concentração de poderes, sem garantias verticais e horizontais ao exercício das suas competências; a ineficiência administrativa com recrutamento do tipo familiar, partidário e ausência do critério da meritocracia e qualidade; a insuficiência da disciplina/repressão, tardia, onerosa, redutora e seletiva; a não-contenção das despesas eleitoral/falta de disciplina financeira interna; a ineficácia dos instrumentos de controlo.

Ao longo das muitas marés de reforma que tiveram lugar nos últimos 30 anos na Administração Pública, os sucessivos governos tentaram lidar com a situação na perspetiva do mal menor.

Essa perspetiva pragmática parece ter prevalecido em muitos países da OCDE e, naturalmente, em Portugal. Em 1993, a Secretária de Estado da Modernização Administrativa apontava a "Carta Deontológica do Serviço Público”, recém-aprovada, como solução, escrevendo:

Constitui uma síntese dos comportamentos que se espera de um funcionário público e pretende ser um modelo para a sua ação no quotidiano. Sem esquecer as limitações humanas dos funcionários e o seu desejo constante de aperfeiçoamento e disciplina, a Carta é

4 Entendida como desvio de poder; criar dificuldades para vender facilidades; apropriação para fins particulares de poderes públicos; comportamento desviante relativamente a padrões legais ou sociais. 
um guia moral, e por isso mesmo se coloca aos níveis mais elevados de exigência das consciências individuais. Os deveres éticos, lembra a Carta, ultrapassam os meros deveres jurídicos, deixando para estes as incidências disciplinares e reservando para os primeiros a censura coletiva. (CARTA DEONTOLÓGICA DO SERVIÇO PÚBLICO, RCM, n.18/93, de 18 de fevreiro, publicada no Diário da República, $1^{\mathrm{a}}$ série $-\mathrm{B}$, n. $^{\circ}$ 64, de 17/03/1993)

A Carta Deontológica baseia-se em valores considerados fundamentais do Serviço Público: em primeiro lugar, o Serviço Público como razão de ser da própria Administração, a legalidade como referência da ação, a neutralidade política, económica e religiosa, a responsabilidade e a competência como atributos do profissionalismo; depois, a integridade como condição de liberdade individual.

Os valores fundamentais do Serviço Público são concretizados em deveres nos três âmbitos em que os funcionários entram em relação na sua atividade profissional:

a) Deveres para com os cidadãos, entendidos em sentido muito amplo, que compreenda todas as entidades, individuais ou coletivas, que se dirigem à Administração.

b) Deveres para com a Administração, envolvendo no mesmo conjunto os deveres para com o Serviço Público, colegas e superiores hierárquicos.

c) Deveres para com os órgãos de soberania, os órgãos de governo próprios das Regiões Autónomas e os titulares dos órgãos autárquicos, titulares do poder político com quem os funcionários públicos devem estreitamente colaborar, sem esquecer a posição privilegiada que nesta matéria o Governo deve assumir, dado a sua qualidade constitucional de órgão superior da Administração Pública.

A questão que hoje se coloca é a da utilidade da Carta Deontológica. Que efeito veio provocar nas formas de pensar, sentir e agir da Administração, quer ao nível do sistema jurídico quer ao nível dos seus funcionários? Facilmente se reconhece que a utilidade foi nula. Por um lado, em 
vários cursos sobre ética, ministrados por nós, para um número superior a um milhar de dirigentes da Administração Pública Portuguesa, entre 2005 e 2012, nos quais sempre se inquiriu acerca da sua representação social sobre o impacto desta carta, a resposta foi, invariavelmente, a mesma: "Documento colorido em papel couché, que se guarda na gaveta e acabou por ir parar ao cesto dos papéis inúteis”.

Por outro lado, os relatos da comunicação social sobre casos de corrupção em Portugal vieram progressivamente aumentando nos últimos 30 anos. Num inquérito à opinião pública lançado em 2009 foram obtidos resultados surpreendentes. Dentre os inquiridos, $60 \%$ responderam que a corrupção aumentou nos últimos três anos; 29\%, que pagam luvas à polícia; $80 \%$ julgam que os partidos políticos são corruptos; $25 \%$ disseram que pagaram luvas no último ano. No mesmo contexto, cerca de $63 \%$ dos portugueses responderam tolerar a corrupção desde que produza efeitos benéficos para a população e $84 \%$ consideraram ineficaz o combate à corrupção. A corrupção do tipo "Zé do Telhado" (que favorece os mais fracos) parece ainda aceite em Portugal.

Pela OCDE, Portugal era ainda visto no início deste milênio, como um país que não tinha uma estratégia global de combate à corrupção na Administração Pública; onde há funcionários que pela sua função deveriam denunciar casos suspeitos de enriquecimento ilícito e que não o fazem; onde os inquéritos patrimoniais acerca do enriquecimento ilícito não são levados a sério.

Apesar dessa Carta Deontológica, Portugal tem de ser ativo na luta contra o suborno de funcionários públicos nas transações económicas internacionais e entre o setor público e privado; as transferências abusivas de agentes públicos para o sector privado não estão regulamentadas de forma satisfatória, não havendo mecanismos adequados de controlo; não existe proteção adequada a quem denunciar casos de corrupção; os agentes da Autoridade Tributária não recebem diretivas nem formação em matéria de deteção e sinalização de casos de corrupção interna à própria autoridade.

No Índice de Percepção da Corrupção (IPC) de 2012, Portugal obteve 63 pontos e a posição 33 no ranking dos 176 países observados. Nesse 
mesmo ano, a Dinamarca, a Finlândia e a Nova Zelândia pontuaram em primeiro lugar, graças à robustez do seu sistema de acesso à informação, que fomenta a prestação de contas e a responsabilização, assim como em virtude do seu sistema de regras de conduta para dirigentes e funcionários. O Afeganistão, a Coreia do Norte e a Somália apresentam os valores mais baixos do ranking provocado pela falta de transparência na conduta dos dirigentes ${ }^{5}$.

Não será despiciendo realçar que dois terços dos países observados apresentaram valores inferiores a 50, ou seja, o tema da corrupção, associada ao abuso de poder, recebimentos indevidos, em dinheiro ou espécie, para benefício pessoal, tráfico de influências é hoje o tema central da administração pública ao nível mundial.

Apesar de tudo, Portugal, na última década, tem aperfeiçoado o enquadramento jurídico relativo à corrupção e ética, criando unidades especializadas no combate à corrupção. Consistente com isto, verifica-se que o país vem, lentamente, a subir no IPC, tendo obtido o valor 58 em 2009; 60 em 2010; e 61 em 2011. A esse facto não pode ser alheio a criação do Conselho de Prevenção da Corrupção ${ }^{6}$, entidade administrativa independente que funciona junto do Tribunal de Contas e tem como fim desenvolver, nos termos da lei, uma atividade de âmbito nacional no domínio da prevenção da corrupção e de infrações conexas de acordo com o artigo 1 . $^{\circ}$ da Lei n. 54/2008.

Caminha nesse sentido o facto de nos estatutos da Comissão de Recrutamento e Seleção para a Administração Pública (CReSAP), entidade administrativa independente, ser atribuída pelo legislador uma responsabilidade acrescida em matéria de ética. Com efeito, a alínea $f$ do artigo 11 da Lei n. 64/2011, de 22 de dezembro de 2011, institui que compete à CReSAP "[...] promover as boas práticas de gestão e ética para titulares de cargos de direção superior na Administração Pública [...]” (PORTUGAL, 2011, art., 11) e, na alínea $g$, dos mesmos estatutos, “[...] promover

5 O IPC avalia os países numa escala de 0-100 onde 0 significa muito corrupto e 100 ausência de corrupção, disponível em; <http://cpi.transparency.org/cpi2012/>. Acesso em: $1^{\circ}$ out. 2014.

6 Disponível em: <http://www.cpc.tcontas.pt>. Acesso em: $1^{\circ}$ out. 2014. O Conselho de Prevenção da Corrupção foi criada pela Lei n. 54/2008, de 4 de setembro de 2008. 
a aprovação e adoção de princípios orientadores para códigos de conduta destinados a titulares de cargos de direção superior na Administração Pública" (PORTUGAL, 2011, art. 11). Aliás, esse é um tema central de toda a pesquisa na área da "boa governança".

\section{3 Ética: a tensão entre justiça e liberdade}

Se a Nova Gestão Pública, ao introduzir um novo programa de gestão, derrubou os sistemas de controlo tradicionais sem ter o cuidado de os substituir, e se esse facto fez eclodir práticas corruptas entre funcionários, dirigentes e gestores públicos, surge naturalmente a pergunta: quem vai pôr termo a isso? Assim, há a percepção de que é dever de alguém acabar com a corrupção, e isso passa pela adoção de padrões éticos de conduta. Por isso, nesse ponto discutir-se-á de que forma será mais adequado proceder à elisão da corrupção ou, antes, ao seu controlo.

Quando um país como a Finlândia apresenta um valor de 95 e o Afeganistão de 17, pode colocar-se a pergunta: há ou não corrupção na Finlândia? A resposta será que a corrupção existe na Finlândia porque não obteve os 100 pontos. Conclusão óbvia: então também é corrupta, tal como é o Afeganistão.

A questão do ser ou não ser corrupto ou ético é perigosa, dado que tenderá a colocar no mesmo saco a Finlândia e o Afeganistão. À pergunta sim ou não, não há como fugir, embora se saiba que existe um abismo a separar, do ponto de vista ético ou da corrupção, estes dois países. Por isso, o caminho do ser ou não ser não se apresenta como uma boa solução.

Afigura-se, pois, que a ética é menos um ponto que se atinge, ou seja, uma constatação, e mais uma aspiração, uma direção que se toma. Usando uma metáfora chinesa, poder-se-ia dizer que será como a estrela polar, que não existe para ser atingida, não deixando por isso de ser fundamental na orientação da ação. Mesmo que na esfera individual ou organizacional, num determinado momento, fosse atingido o ponto máximo de perfeição; logo, no momento seguinte, dado tratar-se de algo 
que é por natureza instável, se perderia para continuar a prosseguir o caminho da aspiração.

Isso porque o que se constata pertence ao indicativo do verbo, "é". O que se aspira pertence ao "deve" ser, ou seja, o imperativo ou o conjuntivo do modo verbal. Ora, a linguagem do "dever ser" pertence ao domínio das aspirações, dos ideais.

Nesse ponto há dois níveis do dever ser: um, que cobre os mínimos que se deve exigir a outrem; o outro, o da virtude, que não deve ser imposto, nem legislado, mas que se preza quando se vê praticado por alguém. É por isso que se diz que "quem faz o que deve a mais não é obrigado", mas por tal não merece qualquer recompensa. E, pelo contrário, quem não cumpre merece censura. É esse o limiar da virtude, que se encontra além e transcende, o do dever. (ALMEIDA; BRÁS, 2012)

Kant distingue duas maneiras como a razão pode comandar a vontade, dois tipos diferentes de imperativos. Um tipo de imperativo hipotético e condicional: se quer X, então faça Y; e outro que é incondicional e, por isso, categórico. No caso de a ação ser boa por causa de outra coisa trata-se do hipotético. Se a ação é representada como boa em si mesma e, por conseguinte, necessária para uma vontade conforme a razão, então o imperativo é categórico.

Nesse sentido, ele recomenda que se aja apenas segundo uma máxima, regra ou princípio tal que possa ao mesmo tempo ser lei universal. Em concreto, está a afirmar que se deve agir apenas segundo princípios que se poderia universalizar sem contestação, por exemplo, se todos mentem nunca mais se poderá confiar em ninguém. Aliás essa máxima facilmente se converte também em utilitarista na doutrina: não mintas porque todos saem prejudicados. (STUART MILL, 2000, p. 182)

A força moral do imperativo categórico torna-se mais clara na formulação que visa "tratar as pessoas como fins" e não meios e "fazê-lo como se fosse uma lei universal". O "não faças aos outros o que não queres que façam a ti". O respeito kantiano é o respeito pela humanidade como tal por uma capacidade racional que existe, sem distinção em todos nós, ou seja, como "[...] seres humanos que é mais exigente do que ape- 
nas com os mesmos direitos que nós. (KANT, apud ALMEIDA; BRÁS, 2012.)

Para Kant agir moralmente é agir por dever - por causa da lei moral. A lei moral corresponde ao imperativo categórico, o princípio que exige que se tratem as pessoas com respeito, como fins em si mesmas. Essa é a única maneira de ser livre. Eu só ajo livremente quando atuo em conformidade com o imperativo categórico. Quando a minha ação é comandada pelo imperativo hipotético não sou verdadeiramente livre na medida em que me encontro condicionado por algum interesse ou fim exterior a mim.

Rawls (1993) parece-nos ter ido mais longe que Kant. A partir de uma "posição original", a humanidade celebraria um acordo sobre os princípios de um código ético para a humanidade, englobando, portanto, todos os seres humanos. Todos nele participariam e delineariam em conjunto esse código. Ora, por nunca saberem se aquela regra se lhes aplicaria, ter-se-ía o cuidado de "maximizá-la". Imagine-se a cena doméstica entre dois filhos a querem o mesmo bolo, em que o pai estabelece a regra de que quem cortar o bolo é o último a servir-se. Quem cortar o bolo será certamente o mais justo que lhe for possível.

Aqui trata-se de elaborar um conjunto de princípios que qualquer membro participante considere equitativamente justo. Depois de celebrar esse acordo, passamos a ter princípios, alguns de caráter deontológico e outros de carácter teleológico, em que a bondade ou a maldade de um ato é decidida consoante os resultados esperados. (RAWLS, 1993)

Em qualquer dos casos, há um conjunto de valores que a modernidade nos legou e que em geral se aceita, isto é, em ética há valores universais; o que não é universal é a sua aplicação, pois ela depende dos contextos culturais, nomeadamente das diversas administrações públicas. Os resultados das negociações de princípios podem variar entre culturas; as aspirações humanas, porém, permanecem idênticas nas suas estruturas latentes. 


\section{Código versus Comportamento Ético}

A edição de Inverno de 1999 da Revista Public Personnel Management foi dedicada ao tema "Etica na atual gestão de recursos humanos". Ora esse número especial da revista teve a vantagem de clarificar um ponto: a lei não é suficiente para estabelecer as fronteiras da conduta ética. (MENZEL, 1999, p. 519)

No mesmo sentido vão os resultados da investigação conduzida pela administração tributária holandesa. Nesse trabalho é reconhecida a limitada utilidade dos códigos de ética para fomentar a confiança nas instituições públicas, assim como a fraca correlação entre tais códigos e a mudança comportamental dos funcionários. Os códigos ficam bem na fotografia da avaliação externa das instituições mas pouco valem como bússolas orientadoras da ação individual de cada funcionário (VAN BLIJSWIJK, 2004).

Chegados a esse ponto, apresenta-se a questão de saber qual a melhor estratégia para colocar a administração - sistema e pessoas - na direção certa da ética e no controlo da corrupção. O que pode ter de fazer-se para além dos códigos de ética?

Em Portugal, desde a publicação da Resolução do Conselho de Ministros n. ${ }^{\circ}$ 18/93, de 18 de fevereiro de 1993, passou a dar-se importância ao tema. Se é verdade - o caso de Portugal confirma-o - que a luta contra a corrupção e a prossecução na direção do comportamento ético na Administração Pública parece estar para além de códigos de ética, também é verdade que, no preâmbulo da referida resolução, era explicitamente referido que "[...] a divulgação da Carta será acompanhada de ações de formação, encontros e seminários".

Tudo isso faltou. O Secretariado para a Modernização Administrativa ainda distribuiu a Carta Deontológica, mas nunca, por exemplo, o Instituto Nacional de Administração (INA) integrou esta orientação nas suas ações de formação, nem os dirigentes superiores da Administração usaram a Carta nos encontros periódicos com os seus funcionários, isto é, ficou por cumprir o essencial e mais difícil - o trabalho com as pessoas. "A foma como os líderes éticos tratam os membros da sua equipa constitui a 
base para que as coisas aconteçam na prática. Não se trata apenas de uma mera questão de integridade pessoal do líder mas antes da capacidade do lider para tomar decisões éticas e para socializar com tais valores os seus seguidores". ( LAWTON et al. 2012, p. 162)

Assim, em face da ineficácia da Carta Deontológica, propõe-se neste trabalho a criação de uma arquitetura ética. Significa isto que se não pode atuar apenas sobre uma variável do sistema organizacional e comportamental, mas sobre todas. A Carta Deontológica, ou um código ético, constitui apenas um elemento. Em si mesmo, pouco ou nada valerá. No entanto, se for gerido no conjunto dos diversos elementos que integram a arquitetura, então, passa a ter significado.

O processo de efetivação da ética passa por uma real vontade política para que se constitua de uma forma homogénea e global, valendo de muito pouco as medidas desgarradas. Ao criar-se as estruturas específicas de gestão da ética, possibilita-se não apenas um tratamento a posteriori das eventuais ocorrências éticas, como dilemas, conflito de interesses. Também se pode potenciar a criação de mecanismos de prospecção e antecipação de problemas éticos, possibilitando a sua resolução de uma forma mais harmoniosa.

Assim, a nossa proposta abrange o nível macro e o micro. Ao nível macro, importa criar uma arquitetura ética baseada nos seguintes pilares: vontade política, marco legal, mecanismo de prestação de contas e responsabilização, código de ética, processos de socialização dos indivíduos. Ao nível micro, essa arquitetura deve contemplar: carta de missão do dirigente, agenda de reuniões periódicas, quadro de avaliação e responsabilização (QUAR), programa de formação, avaliação bianual com o membro do governo com tutela ou superintendência sobre o organismo.

a) Vontade política: se o governo, isto é, cada um dos seus membros (ministros e secretários de estado), não assumir a ética como tema central da sua atuação dificilmente o elefante irá dançar. A terapêutica contra a corrupção passa por uma assumida estratégia nacional contra a corrupção; a corrupção combate-se pela prevenção para reduzir a desconfiança e a suspeição e a complacência, a começar na pequena dimensão. 
b) Marco legal: um ordenamento jurídico eficaz é indispensável, que não se coaduna com legislação avulsa toda a vez que surge um problema, ao sabor da comunicação social. Produção de legislação que obrigue eficazmente à declaração de interesses afigura-se, hoje, em Portugal, de importância redobrada. Por fim, mas não menos importante, a celeridade da justiça. Justiça que tarda não é justiça.

c) Transparência, como prestação de contas e responsabilização: exige a criação de mecanismos de monitorização, como questionários internos e externos, estruturas de apoio ao desenvolvimento, implementação e auditoria, introdução de um mais forte apelo à participação ativa dos cidadãos nas denúncias de más práticas.

d) Códigos de conduta: quando adequados, constituem um aspeto de entre um conjunto de elementos a não descurar. $\mathrm{O}$ problema é elegê-los, por serem, eventualmente, o mais fácil de implementar, como demiurgo salvador. Os códigos de ética são simplesmente códigos e não passam disso, a sua importância depende da sua utilização.

e) Mecanismos de socialização e acompanhamento profissional: aqui deve residir o foco principal da preocupação de políticos e dirigentes. Ações de formação em ética, identificação das situações mais sugestíveis de fraude, discussões periódicas formais sobre o assunto, aconselhamento e acompanhamento são os segredos da arquitetura que aqui propomos.

Ao nível micro, ou institucional, para que o elefante dance, torna-se imprescindível que, em cada instituição, a ética esteja na agenda e, por conseguinte, seja montada uma arquitetura que contemple os seguintes pilares:

a) "Carta de missão" e "contratos de gestão": a "carta de missão" é entregue pelo membro do Governo e subscrita pelos titulares de

\footnotetext{
7 De acordo com o Estatuto do Pessoal Dirigente da Administração, (Lei n. 2/2004), na carta de missão são definidos de forma explícita os objetivos, devidamente quantificados e calendarizados, a atingir no decurso do exercício de funções. Os contratos de gestão são o equivalente para os gestores de empresas públicas (artigo 18 do Decreto-lei n. 71/2007, de 27 de março de 2007.
} 
cargos de direção superior no momento da sua designação. Nos termos da lei, é a cartilha para a avaliação dos dirigentes superiores da Administração Central do Estado, direta ou indireta. Nos contratos de gestão destinados aos gestores de entidades públicas empresariais (EPE) ou de sociedades anónimas (SA) de capital público, o Governo fixa os parâmetros da eficiência da gestão e outros objetivos específicos nos quais se propõe que esteja contemplada a ética.

b) Agenda de reuniões periódicas: se gerir é obter resultados através da colaboração dos outros, não se entende que um dirigente superior ou um gestor público possa descurar o papel benéfico das reuniões periódicas com o seu staff mais direto e, uma ou duas vezes no ano, com todo a sua comunidade laboral. Tais reuniões/encontros devem ser aproveitados para discutir, entre outras, questões éticas, tais como avaliar o plano de prevenção da corrupção ${ }^{8}$, que nos termos da lei está anualmente exposto no sítio eletrônico do organismo.

c) Quadro de avaliação e responsabilização (QUAR) ${ }^{9}$ : os dirigentes são penalizados ou gratificados pelos indicadores que anualmente possam apresentar neste quadro. Tratando-se de um quadro de indicadores de gestão crítico para o bom funcionamento do organismo, recomenda-se que haja, nos objetivos ligados à qualidade, indicadores referentes à ética e à corrupção.

d) Programa de formação: todos os organismos no seu programa anual de formação devem ter em todas as ações previstas uma parte destinada à sensibilização sobre ética, para além de cursos especificamente dedicados ao seu aprofundamento.

e) Avaliação bianual com o membro do governo com tutela ou superintendência sobre o organismo: se o membro do governo não fala, significa que não the atribui importância. Ninguém consegue ser herói a vida toda. Um dirigente esforçado é capaz de, com algum

8 Disponível em: <http://www.tcontas.pt/pt/plano_risco/plano_prevencao.pdf. Acesso em: $1^{\circ}$ out. 2014.

9 A avaliação de desempenho de cada serviço assenta num quadro de avaliação e responsabilização (QUAR), artigo $10^{\circ}$ da Lei n. 66-B/2007. 
esforço, colocar a ética e a corrupção na agenda do seu organismo. Todavia, se o membro do governo com tutela ou superintendência não valorizar este seu trabalho, muito em breve a vontade esmorecerá e o assunto tomará o rumo dos papéis inúteis.

É indispensável conceber as organizações públicas e construí-las tendo por base a questão fulcral dos novos tempos: a ética. As organizações são como peças de teatro. Há uma distinção entre a peça escrita como obra literária e a sua representação por atores. Dir-se-ia que a peça como obra literária representa o sistema organizacional e quando está a ser representada além do sistema organizacional está o conjunto de atores, ou seja, o sistema comportamental. Os atores, mais ou menos, respeitam a prescrição do papel, o equivalente à descrição de funções no sistema organizacional, mas não deixam de dispor de margem de liberdade na interpretação e aplicação do mesmo. Por exemplo, o Rei Lear, apesar das limitações do papel que William Shakespeare lhe confere, não deixa de ter interpretações mais ou menos brilhantes, conforme o caráter dos atores que o encarnam.

Dessa metáfora pode, por analogia, verificar-se que, no que às organizações públicas diz respeito, importa que nos papéis, ou seja, no conjunto dos procedimentos e descrição de funções, a ética (o dever que a todos deve ser imposto) esteja presente. Se estiver, o papel do ator estará mais facilitado e maior dificuldade terá em transgredir.

Ora, desse mínimo que a todos deve ser imposto, diferente da virtude que apenas a cada um diz respeito, a OCDE adotou uma recomendação sobre a melhoria da conduta ética no serviço público em 1998. A OCDE reconhece que os governos, não obstante possuírem diferentes ambientes culturais, políticos e administrativos, se confrontam frequentemente com desafios éticos semelhantes, e as respostas evidenciadas pela sua ética de gestão apresenta características comuns.

Assim, recomenda-se que os padrões éticos do serviço público devem ser claros; os padrões éticos deverão revestir forma legal; formação ética deverá ser disponibilizada aos funcionários; os funcionários devem conhecer os seus direitos e obrigações perante situações de risco ético; compromisso político com a ética deve reforçar a conduta dos funcioná- 
rios; o processo de tomada de decisão deverá ser transparente e aberto ao escrutínio público; devem existir orientações claras para as relações entre o sector público e o sector privado; os dirigentes dos serviços públicos devem patentear e promover conduta ética; as políticas de gestão, os procedimentos e as práticas devem promover a conduta ética; as condições laborais e a gestão de recursos humanos devem promover a conduta ética; mecanismos adequados de responsabilização devem ser implementados no serviço público; adequados procedimentos e sanções devem ser postos em prática para corrigir comportamentos incorretos.

Verifica-se que a arquitetura ética apresentada neste ponto integra todas as recomendações contempladas nesses 12 princípios da OCDE.

Neste trabalho pretendeu dar-se uma nova organização a esses princípios, integrando-os numa arquitetura ética com dois níveis: macro e micro. Simultaneamente procurou dar-se-lhes maior operacionalidade integrando-os no contexto de Portugal.

\section{Conclusão}

O tema da corrupção e da ética no serviço público ganhou força e integra a agenda política e de investigação no ensino em Portugal. Todavia, não há certezas quanto às razões, isto é, se elas se prendem com o facto de políticos e dirigentes/gestores públicos serem mais corruptos, terem maior exposição mediática, ter havido alteração dos sistemas de controlo, ou com o facto de a corrupção constituir uma ameaça ao crescimento econômico.

Por outro lado, a ética é função da negociação da minha liberdade e da liberdade de outrem, e nessa qualidade está permanentemente a ser aferida. A justiça e a liberdade são as questões centrais da ética moderna. Um indivíduo quer a liberdade para satisfazer os seus interesses e desejos, mas, como não está isolado na selva, os restantes indivíduos também o querem. Ora, a tensão entre uns e outros é que gera a necessidade de se procurar um equilíbrio, ou seja, uma cedência equilibrada de algumas liberdades para que outros também possam exercer as suas. É precisamente 
essa busca de equilíbrios que nos leva a pensar que a corrupção deverá ser controlada e a ética permanentemente aspirada.

O elefante não dança, isto é, a mudança na cultura organizacional não acontece se não existir, direta ou indiretamente, uma arquitetura ética que contemple os dois níveis - o macro e o micro. Os códigos de conduta, produzidos no nível macro, só serão úteis se, através de processos de socialização e de acompanhamentos dos indivíduos, forem trabalhados, discutidos e transformados em planos de ação. A reforma da administração pública tem de ultrapassar a estreita agenda da nova gestão pública encarando a questão da ética como algo de substancial e não meramente retórico.

Acresce que, para além dos dois níveis, é indispensável a articulação entre o sistema organizacional e o comportamental. A questão da ética e do controlo da corrupção situa-se no desafio de seduzir os atores a desempenharem o papel que se encontra no código. O código, em si mesmo, não passa de obra literária; a conduta ética está para além do código, que é um meio e não um fim.

\section{Referências}

ALMEIDA, Onésimo T.; BRÁS, João M. Utopias em dói menor. Lisboa: Gradiva, 2012.

ARAÚJO, Joaquim. Da Nova Gestão Pública à Nova Governação Pública. In: SILVESTRE, Araújo. Coletânea Administração Pública. Lisboa: Escolar, 2012.

ARISTÓTELES. A Política, Livro VII 1323. Lisboa: Presença, 1965. BILHIM, João; NEVES, Barbara Barbosa. New ethical challenges in a changing Public Administration. Paper presented at the conference of the American Society for Public Administration and the European Group for Public Administration, 'Ethics and Integrity of Governance: The First Transatlantic Dialogue’, Leuven, Belgium, 2005. 
BILHIM. Ciência da administração. Lisboa: Universidade Aberta, 2008.

BJUR W. E.; CAIDEN G. E. On Reforming Institutional Bureaucracies. International Review of Administration Sciences, USA, v. 44, p. $359-65,1978$.

BLIJSWIJK, Jacques A. M. et al. Beyond Ethical Codes: the Management of Integrity in the Netherlands Tax and Customs Administration. Public Administration Review, USA, v. 64, n. 6, November/December, 2004.

CHANDLER, Ralph Clark. Deontological Dimensions of Administrative Ethics. In: COOPER, Terry L, (Ed.). Handbook of Administrative Ethics. New York: Marcel Dekker, 1994. p. 147-156.

COOPER, Terry L. Handbook of Administrative Ethics, New York: Marcel Dekker, 1994.

FREDERICKSON, H. George. The Spirit of Public Administration. San Francisco: Jossey-bass, 1997.

KANT, Immanuel (1788). Crítica da razão prática. Tradução de Artur Morão. Lisboa: edições 70, 1994.

LADRIÈRE, Jean. L'Éthique dans l'Univers de la Rationalité. Namur: Artel e Québec, Fides, 1997.

LAWTON, Alan et al.. Ethics and Management in the Public Sector. London: Routledge, 2012.

MENZEL, D. C. The Morally Mute Manager: Fact or fiction? Public Personnel Management, USA, v. 28, p. 515-29, 1999.

MILL, S. A liberdade: Utilitarismo. São Paulo: Martins Fontes, 2000. MOZZICAFREDO, J. A Responsabilidade e a Cidadania na Administração Pública. Sociologia, Problemas e Práticas, Lisboa, PT, n. 40, p. 9-22, 2002.

OCDE - ORGANIZAÇÃO PARA COOPERAÇÃO DE DESENVOLVIMENTO ECONÓMICO. Ethics in the Public Service: currents issues and practices. Paris: OCDE Publications, 1996. 
PORTUGAL. 1993. Resolução do Conselho de Ministros, $n .^{\circ}$ 18/93, de 18 de fevereiro, publicada no Diário da República, $1^{\mathrm{a}}$ série $-\mathrm{B}, \mathrm{n}^{\mathrm{o}}{ }^{64}$, de 17/03/1993.

PUGH, Darrell L. The Origins of Ethical Frameworks in Public Administration. In: Ethical Frontiers in Public Management: Seeking New Strategies for Resolving Ethical Dilemmas, edited by James S. Bowman, p. 9-33. San Francisco: Jossey-Bass, 1991. RAWLS, John. Uma teoria da justiça. Lisboa: Presença, 1993. RICOEUR, Paul. O Justo. Tradução Paris. Lisboa: Piaget, Seuil, 1995. SANDEL, Michael J. Justiça. Lisboa: Presença, 2011.

João Abreu de Faria Bilhim é Professor Catedrático do Instituto Superior de Ciências Sociais e Políticas (ISCSP) da Universidade de Lisboa (UL), Diretor do Departamento de Administração Pública do ISCSP/UL, Presidente da Comissão de Recrutamento e Seleção para a Administração Pública Portuguesa (CReSAP), e Fundador do Centro de Administração e Políticas Públicas (CAPP), centro de pesquisa avaliado pela Fundação par a Ciência e Tecnologia (FCT) de Portugal com a classificação máxima de excelente.

E-mail: bilhim@iscsp.ulisboa.pt

Endereço profissional: Instituto Superior de Ciências Sociais e Políticas (ISCSP) da Universidade de Lisboa (UL). Rua Prof. Almerindo Lessa, Polo Universitário do Alto da Ajuda, 1349-055, Lisboa, Portugal. 